\title{
Effects of surgical and FFP2/N95 face masks on cardiopulmonary exercise capacity
}

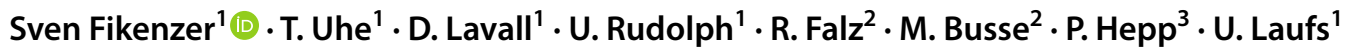

Received: 27 May 2020 / Accepted: 30 June 2020 / Published online: 6 July 2020

(c) The Author(s) 2020

\begin{abstract}
Background Due to the SARS-CoV2 pandemic, medical face masks are widely recommended for a large number of individuals and long durations. The effect of wearing a surgical and a FFP2/N95 face mask on cardiopulmonary exercise capacity has not been systematically reported.

Methods This prospective cross-over study quantitated the effects of wearing no mask (nm), a surgical mask (sm) and a FFP2/N95 mask (ffpm) in 12 healthy males (age $38.1 \pm 6.2$ years, BMI $24.5 \pm 2.0 \mathrm{~kg} / \mathrm{m}^{2}$ ). The 36 tests were performed in randomized order. The cardiopulmonary and metabolic responses were monitored by ergo-spirometry and impedance cardiography. Ten domains of comfort/discomfort of wearing a mask were assessed by questionnaire.

Results The pulmonary function parameters were significantly lower with mask (forced expiratory volume: $5.6 \pm 1.0 \mathrm{vs}$ $5.3 \pm 0.8$ vs $6.1 \pm 1.0 \mathrm{l} / \mathrm{s}$ with sm, ffpm and $\mathrm{nm}$, respectively; $p=0.001$; peak expiratory flow: $8.7 \pm 1.4 \mathrm{vs} 7.5 \pm 1.1 \mathrm{vs}$ $9.7 \pm 1.6 \mathrm{l} / \mathrm{s} ; p<0.001)$. The maximum power was $269 \pm 45,263 \pm 42$ and $277 \pm 46 \mathrm{~W}$ with sm, ffpm and nm, respectively; $p=0.002$; the ventilation was significantly reduced with both face masks $(131 \pm 28$ vs $114 \pm 23 \mathrm{vs} 99 \pm 191 / \mathrm{m} ; p<0.001)$. Peak blood lactate response was reduced with mask. Cardiac output was similar with and without mask. Participants reported consistent and marked discomfort wearing the masks, especially ffpm.

Conclusion Ventilation, cardiopulmonary exercise capacity and comfort are reduced by surgical masks and highly impaired by FFP2/N95 face masks in healthy individuals. These data are important for recommendations on wearing face masks at work or during physical exercise.
\end{abstract}

Keywords Cardiopulmonary $\cdot$ Exercise capacity $\cdot$ Ventilation $\cdot$ Surgical masks $\cdot$ FFP2/N95

\section{Introduction}

Following the outbreak of the SARS-CoV2 pandemic, use of face masks $(\mathrm{fm})$ is widely recommended by international, national and local authorities [1-3]. The aim of the regulations is to reduce the respiratory droplet excretion in

Sven Fikenzer and T. Uhe contributed equally.

Sven Fikenzer

sven.fikenzer@medizin.uni-leipzig.de

1 Klinik und Poliklinik für Kardiologie, Universitätsklinikum Leipzig, Liebigstr. 20, 04103 Leipzig, Germany

2 Institut für Sportmedizin und Prävention, Universität Leipzig, Marschner Str. 29, 04109 Leipzig, Germany

3 Klinik für Orthopädie, Unfallchirurgie und Plastische Chirurgie, Universitätsklinikum Leipzig, Liebigstr. 20, 04103 Leipzig, Germany pre-symptomatic and asymptomatic individuals (source control). The evidence for face masks to reduce respiratory virus infections or to improve clinical outcomes is heterogeneous [4-6]. The role of fine-particle aerosols and environmental factors such as temperature and humidity on respiratory virus transmission is a matter of scientific debate [7]. However, as long as no effective treatment or vaccination against SARS-CoV2 is available, health policies need to rely on non-pharmacological interventions such as social distancing, intensified hand hygiene and the wearing of face masks. Current recommendations to wear a face mask during times of contact to other individuals affect millions of persons. Especially health care professionals are required to wear masks for long periods of time. However, the quantitative effects of medical masks on cardiopulmonary exercise capacity have never been systematically reported.

Disposable surgical masks are intended to reduce transmissions from the wearer to the patient, hand-to-face 
contact and facial contact with large droplets. FFP2/ N95 facepiece respirators meet filtration requirements of small airborne particles, fit tightly to the wearer's face and have been suggested to be more efficacious than surgical masks in reducing exposure to viral infections [8]. They are, therefore, widely used by health care professionals for self-protection, especially during the SARS-CoV2 pandemic. However, randomized trials did not find significant differences between FFP2/N95 and surgical masks in preventing influenza infections or respiratory illness $[9,10]$.

Studies on cardiopulmonary capacity have been performed using respirator masks, e.g., full facepiece masks, filtering air-purifying respirators (APR), air-supplied respirators, blower powered air-purifying respirators (PAPR), and self-contained breathing apparatus (SCBA) [11]. These respirators are better known as "gas masks" that are not used by health care professionals and are not suitable to be worn by the majority of the population. Data on cardiopulmonary capacity wearing medical masks are not available. Since surgical and FFP2/N95 masks are the two most widely used types of medical face masks, they were included in this study protocol.

In addition to health care professionals, information on cardiopulmonary effects of face masks in healthy adults could be important for different groups of individuals. Virus particles in respiratory droplets may be transmitted to a greater extent during different forms of physical exertion, many amateur and professional sports or activities such as singing $[6,12]$. Face masks have, therefore, been discussed as means to engage in these activities for a wide range of individuals. Therefore, this randomized crossover study aimed to provide a detailed quantification of the effect of surgical and FFP2/N95 masks on pulmonary and cardiac capacity in healthy adults.

\section{Materials and methods}

\section{Subjects}

The study was conducted at the Department of Cardiology, University of Leipzig. The 12 active and healthy male volunteers were recruited from medical staff. Subjects with cardiac, pulmonary or inflammatory diseases or any other medical contraindications were not included. The characteristics of the participants are shown in Table 1. The study was conducted in accordance with the latest revision of the Declaration of Helsinki and was approved by the Ethical Committee of the Medical Faculty, University of Leipzig (reference number 088/18-ek). Written informed consent was obtained from all the participants.
Table 1 Baseline characteristics

\begin{tabular}{llc}
\hline Parameter & Unit & Mean \pm SD \\
\hline Age & Years & $38.1 \pm 6.2$ \\
Height & $\mathrm{cm}$ & $183 \pm 7.7$ \\
Weight & $\mathrm{kg}$ & $81.8 \pm 8.4$ \\
Body mass index & $\mathrm{kg} / \mathrm{m}^{2}$ & $24.5 \pm 2.0$ \\
Sports activity & $\mathrm{min} / \mathrm{week}$ & $186 \pm 13$ \\
Heart rate & $\mathrm{bpm}$ & $68.1 \pm 9.3$ \\
Systolic blood pressure & $\mathrm{mmHg}$ & $126 \pm 13.8$ \\
Diastolic blood pressure & $\mathrm{mmHg}$ & $83.1 \pm 6.5$ \\
\hline
\end{tabular}

min minute, $b p m$ beats per minute

\section{Study design}

Medical history was taken using a questionnaire. Subjects received physical examination and vital parameters, body measurements and a resting electrocardiogram (ECG). Each subject performed three incremental exertion tests (IET), one "no mask" (nm), one with surgical mask (sm) and one with FFP2/N95 mask (ffpm). The order of the masks worn was randomly assigned using the GraphPad Quickcalcs online randomization tool [13]. Tests were performed at the same time of day with a minimum of $48 \mathrm{~h}$ between two tests. To assess baseline respiratory function, spirometry for each setting (nm, sm, ffpm) was performed. The participants were blinded with regard to their respective test results to avoid influence by an anticipation bias. Statistical analysis was performed by an independent and fully blinded scientist who was not involved in the conduction of the tests.

\section{Incremental exertion test (IET)}

IET were performed on a semi-recumbent ergometer (GE eBike, GE Healthcare GmbH, Solingen, Germany, Germany) at a constant speed of 60-70 revolutions per minute (rpm). The test began at a workload of $50 \mathrm{~W}$ with an increase of $50 \mathrm{~W}$ within $3 \mathrm{~min}$ (as a ramp) until voluntary exhaustion occurred. Each subject continued for an additional 10-min recovery period at a workload of $25 \mathrm{~W}$.

\section{Masks}

We used typical and widely used disposable FFP2/N95 protective face masks (Shaoguan Taijie Protection Technology Co., Ltd., Gao Jie, China) and surgical masks (Suavel ${ }^{\circledR}$ Protec Plus, Meditrade, Kiefersfelden, Germany), both with earloops.

The spirometry mask was placed over the fm and fixed with head straps in a leak-proof manner (see Fig. 1A1, B1). 
Fig. 1 Fitting of mask and leakage test. Fitting of spirometry mask with sm (A1) and ffpm (B1) and the respective leakage tests with sm (A2) and ffpm (B2)

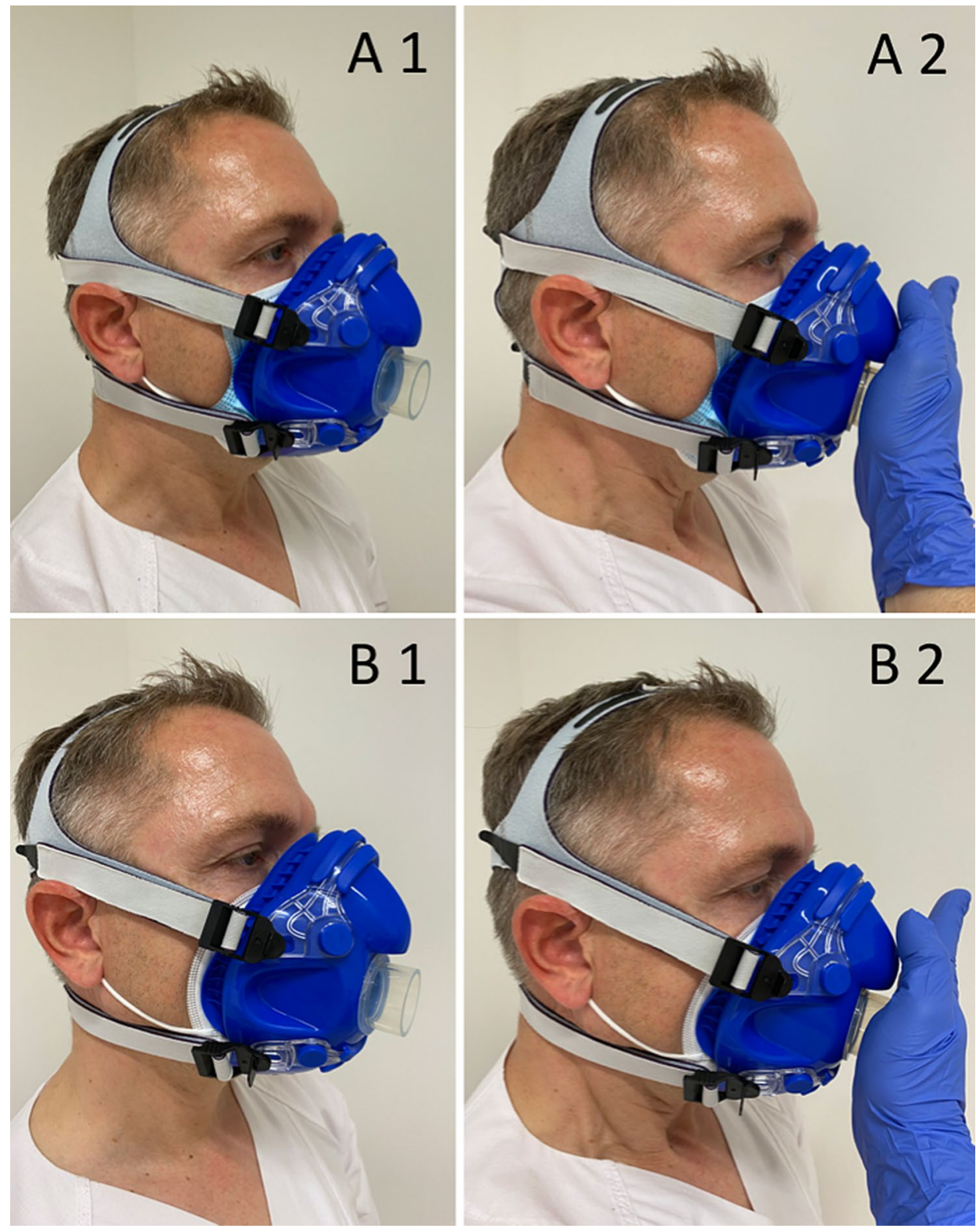

After fitting the spirometry mask, subjects performed (a) inspiration and (b) expiration with maximal force. During both maneuvers, the valve of the mask was closed leading to abrupt stop of the air flow (see Fig. 1A2, B2). The fitting was carefully checked for the absence of any acoustic, sensory or visual indication of leakage (e.g., lifting of the mask, whistling or lateral airflow) by the investigators and the test person. The correct fitting and leak tightness were confirmed before each test was started.

\section{Measurements}

Cardiac output (CO), stroke volume (SV) (measured by impedance cardiography; Physioflow, Manatec Biomedical, Macheren, France), heart rate (HR) (GE-Cardiosoft,
GE Healthcare GmbH, Solingen, Germany), maximum oxygen consumption $\left(V \mathrm{O}_{2 \max }\right)$ and minute ventilation (VE) were monitored continuously at rest, during IET and during recovery. Lung function and spirometry data were collected through a digital spirometer (Vyntus ${ }^{\mathrm{TM}} \mathrm{CPX}$, Vyaire Germany, Hoechberg, Germany). For each modality (nm, sm, ffpm), data of three expiratory maneuvers with 1-min intervals were collected using the best values obtained for maximum forced vital capacity (FVC), forced expiratory volume in 1st second (FEV1), peak expiratory flow (PEF) and Tiffeneau index (TIFF). The arterio-venous oxygen difference was computed using Fick's principle with avDO ${ }_{2}=V_{2} / \mathrm{CO}$. Cardiac work $(\mathrm{CW})$ was measured in joules $(\mathrm{J})$ and calculated according to the formula $\mathrm{CW}=\mathrm{SV}\left(\right.$ in $\left.^{3}\right) \times \mathrm{SBP}$ (in $\mathrm{Pa})$. Capillary blood samples $(55 \mu \mathrm{l})$ were taken from the 
earlobe at baseline and immediately after cessation of maximum load and analyzed (ABL90 FLEX blood gas analyzer, Radiometer GmbH, Krefeld, Germany). Blood pressures (BP) was observed at rest, every 3 min during the IET and after the first 5 min of recovery period.

\section{Quantification of comfort/discomfort}

We used a published questionnaire published by [14] to quantify the following ten domains of comfort/discomfort of wearing a mask: humidity, heat, breathing resistance, itchiness, tightness, saltiness, feeling unfit, odor, fatigue, and overall discomfort. The participants were asked $10 \mathrm{~min}$ after each IET how they perceived the comfort in the test.

\section{Statistical analysis}

All values are expressed as means and standard deviations unless otherwise stated, and the significance level was defined as $p<0.05$. Data were analyzed using Microsoft Office Excel ${ }^{\circledR} 2010$ for Windows (Microsoft Corporation, Redmond, Washington, USA) and GraphPad Prism 8 (GraphPad Software Inc., California, USA). For distribution analysis, the D'Agostino-Pearson normality test was used. For normal distribution, comparisons were made using one-way repeated measures ANOVA with Turkey's post hoc test for multiple comparisons. Otherwise, the Friedman non-parametric test and Dunn's post hoc test were used. The study was powered to detect a difference of $10 \%$ in $V \mathrm{O}_{2 \max }{ }^{\prime}$ $\mathrm{kg}$ between $\mathrm{nm}$ and ffpm.

\section{Results}

\section{Pulmonary function}

The results of the pulmonary function tests are shown in Table 2 . Both sm and ffpm significantly reduce the dynamic lung parameters. The average reduction of FVC was $-8.8 \pm 6.0 \%$ with sm and $-12.6 \pm 6.5 \%$ with ffpm. FEV1 was $-7.6 \pm 5.0 \%$ lower with sm and $-13.0 \pm 9.0 \%$ with ffpm compared to no mask. The peak flow measurement showed that both sm and ffpm significantly reduced the PEF $(-9.7 \pm 11.2 \%$ and $-21.3 \pm 12.4 \%$, respectively $)$.

\section{Incremental exertion test}

The results of IET under different conditions are depicted in Table 3. None of the masks had impact on the examined parameters under resting condition. The average duration of IET compared to the test without mask was slightly decreased by $-29 \pm 40 \mathrm{~s}$ with sm $(p=0.07)$ and significantly decreased by $-52 \pm 45 \mathrm{~s}$ with ffpm $(p=0.005)$. Under maximum load, there was a large reduction of the performance measures Pmax and $V \mathrm{O}_{2 \max }$, especially with ffpm (Fig. 2). Furthermore, these parameters were significantly reduced in ffpm compared to sm.

Assessment of the hemodynamic parameters (Table 3) showed that ffpm decreased $\mathrm{avDO}_{2}$ by $16.7 \pm 11.2 \%$ compared to $\mathrm{nm}$. Stroke volume and cardiac output and cardiac work did not differ significantly $(\mathrm{nm}: 4.3 \pm 0.8 \mathrm{~J}$, sm: $4.7 \pm 1.4 \mathrm{~J}$, ffpm: $4.6 \pm 0.9 \mathrm{~J} ; p=0.29$ ).

The masks showed a marked effect on pulmonary parameters: VE for both sm and ffpm was significantly reduced by $-12.0 \pm 12.6 \%$ and $-23.1 \pm 13.6 \%$, respectively, compared to $\mathrm{nm}$ (see Table 3; Fig. 1). Compared to nm, tests with ffpm showed a significant reduction in breathing frequency with an additional decrease in tidal volume $(-9.9 \pm 11.3 \%$ and $-14.4 \pm 13.0 \%$, respectively). At the same time, a longer inhalation time was observed (sm: $12 \pm 15 \%, p=0.043$; ffpm: $19 \pm 16 \%, p=0.005)$. There were no differences in exhalation time.

Measurements of the metabolic parameters $\mathrm{pH}, \mathrm{PCO}_{2}$, $\mathrm{PO}_{2}$ and lactate and the heart rate recovery did not differ significantly between the three tests (Table 3 ).

\section{Perceived discomfort}

Subjective ratings for different sensations and overall discomfort for sm and ffpm compared to $\mathrm{nm}$ are depicted in

Table 2 Spirometry results

\begin{tabular}{llrrrrrrr}
\hline Parameter & Unit & \multicolumn{1}{l}{$\mathrm{nm}$} & \multicolumn{1}{l}{$\mathrm{sm}$} & \multicolumn{1}{l}{ ffpm } & ANOVA & nm vs sm & nm vs. ffpm & sm vs ffpm \\
\hline FVC & 1 & $6.1 \pm 1.0$ & $5.6 \pm 1.0$ & $5.3 \pm 0.8$ & $<\mathbf{0 . 0 0 1}$ & $\mathbf{0 . 0 0 3}$ & $<\mathbf{0 . 0 0 1}$ & $\mathbf{0 . 0 3 2}$ \\
FEV1 & 1 & $4.3 \pm 0.7$ & $4.0 \pm 0.7$ & $3.7 \pm 0.6$ & $\mathbf{0 . 0 0 1}$ & $\mathbf{0 . 0 0 1}$ & $\mathbf{0 . 0 0 3}$ & 0.068 \\
TIFF & $\%$ & $70.6 \pm 9.7$ & $71.2 \pm 6.9$ & $69.7 \pm 4.9$ & 0.635 & 0.934 & 0.900 & 0.520 \\
PEF & $1 / \mathrm{s}$ & $9.7 \pm 1.6$ & $8.7 \pm 1.4$ & $7.5 \pm 1.1$ & $<\mathbf{0 . 0 0 1}$ & $\mathbf{0 . 0 2 6}$ & $\mathbf{0 . 0 0 1}$ & $\mathbf{0 . 0 4 0}$ \\
\hline
\end{tabular}

Spirometry results of health volunteers wearing no mask (nm), a surgical mask (sm) and a FFP2/N95 mask (ffpm) depicted as mean \pm standard deviation

Significant results are indicated in bold

$F V C$ forced vital capacity, FEVI forced expiratory volume in $1 \mathrm{~s}$, TIFF Tiffenau index, PEF peak expiratory flow, $l$ liter, $s$ second 
Table 3 Results of the incremental exercise test

\begin{tabular}{|c|c|c|c|c|c|c|c|c|}
\hline Incremental exertion test & Unit & $\mathrm{nm}$ & $\mathrm{sm}$ & ffpm & ANOVA & $\begin{array}{l}\mathrm{nm} \\
\mathrm{vs} \mathrm{sm}\end{array}$ & $\begin{array}{l}\text { nm } \\
\text { vs. ffpm }\end{array}$ & $\begin{array}{l}\text { sm } \\
\text { vs. ffpm }\end{array}$ \\
\hline \multicolumn{9}{|l|}{ Rest } \\
\hline \multicolumn{9}{|l|}{ Hemodynamic parameters } \\
\hline HR & bpm & $66.2 \pm 9.3$ & $66.2 \pm 11.8$ & $66.2 \pm 7.2$ & 1.000 & 1.000 & 1.000 & 1.000 \\
\hline SV & $\mathrm{ml}$ & $100 \pm 17.7$ & $105 \pm 22.3$ & $103 \pm 21.0$ & 0.280 & 0.354 & 0.310 & 0.863 \\
\hline $\mathrm{CO}$ & $1 / \min$ & $6.3 \pm 0.7$ & $6.6 \pm 0.7$ & $6.6 \pm 0.9$ & 0.314 & 0.542 & 0.248 & 0.985 \\
\hline $\mathrm{avDO}_{2}$ & $\%$ & $5.4 \pm 1.5$ & $4.7 \pm 1.3$ & $5.1 \pm 0.9$ & 0.346 & 0.307 & 0.837 & 0.623 \\
\hline SBP & $\mathrm{mmHg}$ & $117 \pm 8.7$ & $122 \pm 12.3$ & $121 \pm 12.0$ & 0.399 & 0.474 & 0.529 & 0.977 \\
\hline DBP & $\mathrm{mmHg}$ & $81.9 \pm 6.1$ & $80.1 \pm 6.6$ & $81.0 \pm 6.2$ & 0.569 & 0.494 & 0.836 & 0.907 \\
\hline \multicolumn{9}{|l|}{ Pulmonary parameters } \\
\hline VE & $1 / \min$ & $10.5 \pm 2.5$ & $10.3 \pm 2.6$ & $10.4 \pm 1.9$ & 0.822 & 0.898 & 0.967 & 0.958 \\
\hline Breathing frequency & brpm & $14.8 \pm 2.2$ & $12.9 \pm 2.9$ & $12.5 \pm 2.7$ & 0.006 & 0.051 & 0.016 & 0.601 \\
\hline VT & 1 & $0.7 \pm 0.2$ & $0.8 \pm 0.2$ & $0.9 \pm 0.2$ & 0.146 & 0.465 & 0.125 & 0.770 \\
\hline \multicolumn{9}{|l|}{ Metabolic parameters } \\
\hline $\mathrm{pH}$ & & $7.41 \pm 0.02$ & $7.44 \pm 0.06$ & $7.42 \pm 0.02$ & 0.166 & 0.278 & 0.558 & 0.422 \\
\hline $\mathrm{PCO}_{2}$ & $\mathrm{mmHg}$ & $40.2 \pm 3.4$ & $39.3 \pm 3.6$ & $39.3 \pm 2.2$ & 0.094 & 0.179 & 0.213 & 0.998 \\
\hline $\mathrm{PO}_{2}$ & $\mathrm{mmHg}$ & $111 \pm 4.3$ & $117 \pm 23.1$ & $122 \pm 22.1$ & 0.465 & 0.824 & 0.487 & 0.787 \\
\hline Lactate & $\mathrm{mmol} / \mathrm{l}$ & $1.00 \pm 0.27$ & $0.78 \pm 0.26$ & $1.04 \pm 0.52$ & 0.125 & 0.003 & 0.962 & 0.281 \\
\hline \multicolumn{9}{|l|}{ Maximum load } \\
\hline \multicolumn{9}{|l|}{ Peformance } \\
\hline$P_{\max }$ & W & $277 \pm 45.9$ & $269 \pm 45.1$ & $263 \pm 41.7$ & 0.002 & 0.071 & 0.005 & 0.018 \\
\hline$P_{\max } / \mathrm{kg}$ & $\mathrm{W} / \mathrm{kg}$ & $3.40 \pm 0.5$ & $3.30 \pm 0.5$ & $3.22 \pm 0.4$ & 0.001 & 0.066 & 0.005 & 0.019 \\
\hline$V \mathrm{O}_{2 \max } / \mathrm{kg}$ & $(\mathrm{ml} / \mathrm{min}) / \mathrm{kg}$ & $39.7 \pm 5.8$ & $37.9 \pm 6.0$ & $34.5 \pm 5.3$ & $<0.001$ & 0.063 & 0.001 & 0.013 \\
\hline \multicolumn{9}{|l|}{ Hemodynamic parameters } \\
\hline HR & bpm & $187 \pm 8.3$ & $183 \pm 9.2$ & $182 \pm 11.2$ & 0.106 & 0.031 & 0.107 & 0.964 \\
\hline SV & $\mathrm{ml}$ & $151 \pm 26.4$ & $165 \pm 35.0$ & $164 \pm 20.4$ & 0.086 & 0.166 & 0.074 & 0.979 \\
\hline $\mathrm{CO}$ & $1 / \min$ & $25.8 \pm 4.2$ & $27.3 \pm 5.6$ & $27.0 \pm 3.8$ & 0.342 & 0.435 & 0.422 & 0.964 \\
\hline $\mathrm{avDO}_{2}$ & $\%$ & $12.8 \pm 2.8$ & $11.5 \pm 2.2$ & $10.5 \pm 2.0$ & 0.002 & 0.084 & 0.007 & 0.172 \\
\hline SBP & $\mathrm{mmHg}$ & $214 \pm 18.2$ & $212 \pm 28.5$ & $210 \pm 18.8$ & 0.901 & 0.984 & 0.905 & 0.954 \\
\hline DBP & $\mathrm{mmHg}$ & $88.8 \pm 9.6$ & $95.8 \pm 36.7$ & $89.8 \pm 8.8$ & 0.582 & 0.779 & 0.959 & 0.847 \\
\hline \multicolumn{9}{|l|}{ Pulmonary parameters } \\
\hline VE & $1 / \min$ & $131 \pm 27.8$ & $114 \pm 23.3$ & $98.8 \pm 18.6$ & 0.001 & 0.048 & 0.003 & 0.009 \\
\hline Breathing frequency & brpm & $40.9 \pm 5.1$ & $39.3 \pm 6.2$ & $36.8 \pm 5.9$ & 0.019 & 0.518 & 0.024 & 0.138 \\
\hline VT & 1 & $3.2 \pm 0.7$ & $2.9 \pm 0.5$ & $2.7 \pm 0.4$ & 0.016 & 0.255 & 0.021 & 0.102 \\
\hline \multicolumn{9}{|l|}{ Metabolic parameters } \\
\hline $\mathrm{pH}$ & & $7.27 \pm 0.05$ & $7.32 \pm 0.10$ & $7.31 \pm 0.06$ & 0.158 & 0.216 & 0.065 & 0.989 \\
\hline $\mathrm{PCO}_{2}$ & $\mathrm{mmHg}$ & $34.2 \pm 3.8$ & $34.3 \pm 5.9$ & $34.9 \pm .0$ & 0.726 & 0.999 & 0.560 & 0.943 \\
\hline $\mathrm{PO}_{2}$ & $\mathrm{mmHg}$ & $107 \pm 20.5$ & $116 \pm 23.7$ & $116 \pm 23.2$ & 0.502 & 0.714 & 0.339 & 0.996 \\
\hline Lactate & $\mathrm{mmol} / \mathrm{l}$ & $12.8 \pm 3.09$ & $11.0 \pm 3.91$ & $10.8 \pm 3.12$ & 0.049 & 0.132 & 0.105 & 0.985 \\
\hline \multicolumn{9}{|l|}{ Recovery } \\
\hline \multicolumn{9}{|l|}{ Hemodynamic parameters } \\
\hline HRR-1 min & bpm & $-39.7 \pm 15.9$ & $-38.1 \pm 9.2$ & $-39.9 \pm 11.2$ & 0.203 & 0.055 & 0.611 & 0.781 \\
\hline HRR-5 min & bpm & $-72.5 \pm 24.1$ & $-77.6 \pm 11.5$ & $-77.3 \pm 10.9$ & 0.874 & 0.938 & 0.855 & 0.991 \\
\hline
\end{tabular}

Results of the incremental exercise test of health volunteers wearing no mask (nm), a surgical mask (sm) and a FFP2/N95 mask (ffpm) depicted as mean \pm standard deviation

Significant results are indicated in bold

$H R$ heart rate, $P$ power, $S V$ stroke volume, $C O$ cardiac output, $a v D O_{2}$ arterio-venous oxygen content difference, $S B P$ systolic blood pressure, $D B P$ diastolic blood pressure, $\mathrm{VO}_{2}$ oxygen uptake, $V E$ ventilation, $V T$ tidal volume, $\mathrm{PCO}_{2}$ partial pressure of carbon dioxide, $\mathrm{PO}_{2}$ partial pressure of oxygen, $H R R$ heart rate recovery, bpm beats per minute, $W$ Watt, brpm breaths per minute 
Fig. 2 Effects of wearing a surgical mask (sm) and a FFP2/ N95 mask (ffpm) compared to no mask on maximal power $\left(P_{\max }\right)$, maximal oxygen uptake $\left(V \mathrm{O}_{2 \max }\right)$, ventilation $(\mathrm{VE})$ and overall discomfort. $* p<0.05$; $* * p<0.01 ; * * * p<0.001$
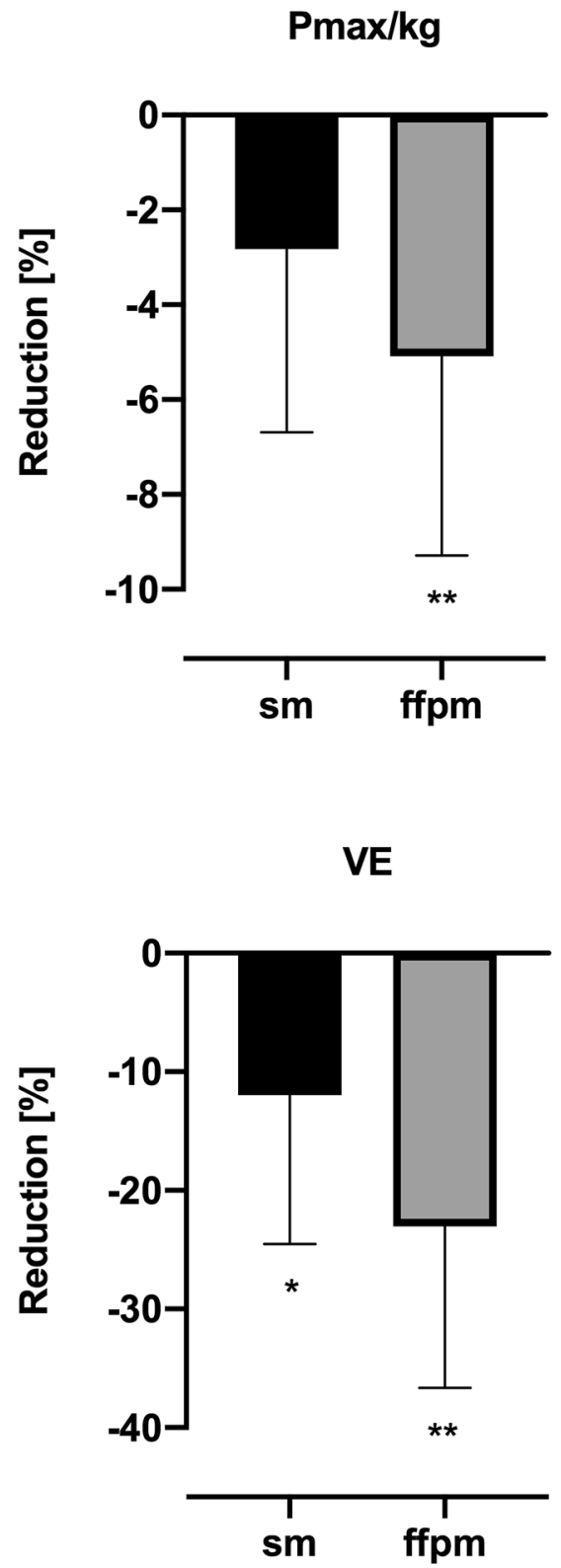

VO2max/kg

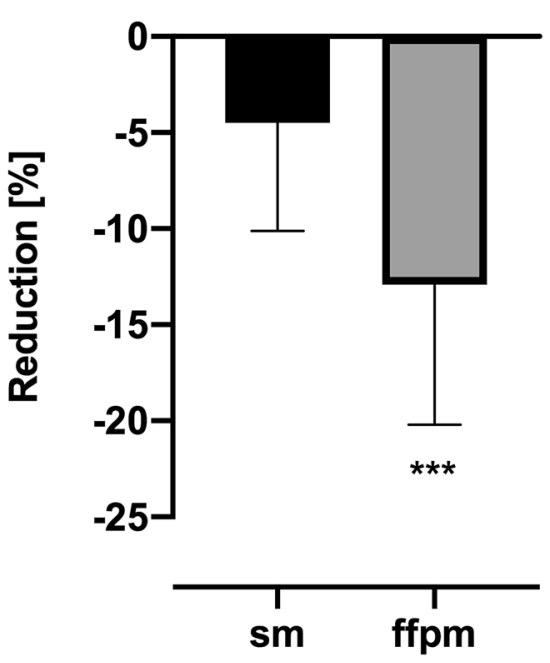

Overall Discomfort

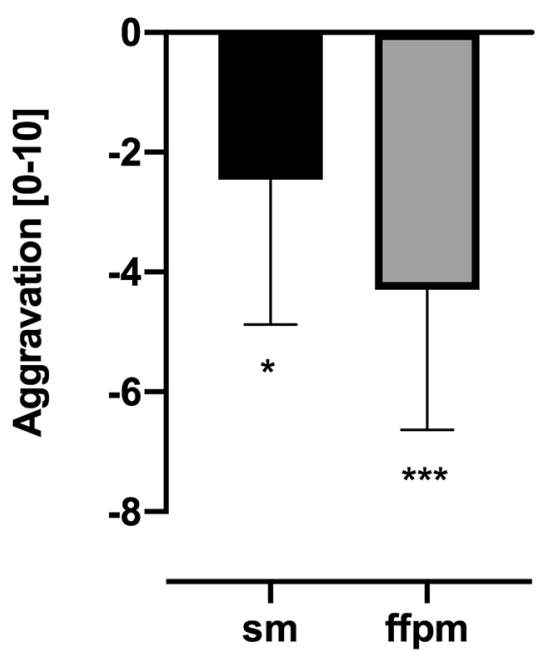

Table 4 Perceived discomfort

\begin{tabular}{llllrlrl}
\hline Discomfort & $\mathrm{nm}$ & $\mathrm{sm}$ & \multicolumn{1}{l}{$\mathrm{ffpm}$} & ANOVA & $\mathrm{nm}$ vs sm & nm vs ffpm & sm vs ffpm \\
\hline Humid & $2.4 \pm 2.0$ & $4.9 \pm 3.2$ & $5.9 \pm 2.2$ & $\mathbf{0 . 0 0 3}$ & 0.069 & $\mathbf{0 . 0 0 1}$ & 0.402 \\
Hot & $2.0 \pm 1.3$ & $4.2 \pm 2.4$ & $6.2 \pm 2.3$ & $<\mathbf{0 . 0 0 1}$ & $\mathbf{0 . 0 1 2}$ & $<\mathbf{0 . 0 0 1}$ & $\mathbf{0 . 0 2 4}$ \\
Breath resistance & $1.7 \pm 1.2$ & $5.4 \pm 1.9$ & $7.4 \pm 2.5$ & $<\mathbf{0 . 0 0 1}$ & $\mathbf{0 . 0 0 1}$ & $<\mathbf{0 . 0 0 1}$ & $\mathbf{0 . 0 4 5}$ \\
Itchy & $1.1 \pm 1.0$ & $3.4 \pm 3.1$ & $4.9 \pm 2.6$ & $\mathbf{0 . 0 0 2}$ & $\mathbf{0 . 0 3 0}$ & $\mathbf{0 . 0 0 1}$ & 0.331 \\
Tight & $1.9 \pm 1.8$ & $3.9 \pm 2.6$ & $6.5 \pm 2.3$ & $<\mathbf{0 . 0 0 1}$ & $\mathbf{0 . 0 3 5}$ & $<\mathbf{0 . 0 0 1}$ & $\mathbf{0 . 0 2 1}$ \\
Salty & $0.7 \pm 1.1$ & $1.6 \pm 1.5$ & $3.5 \pm 2.8$ & $\mathbf{0 . 0 0 3}$ & 0.261 & $\mathbf{0 . 0 1 2}$ & $\mathbf{0 . 0 2 3}$ \\
Unfit & $1.4 \pm 1.2$ & $3.3 \pm 2.3$ & $5.4 \pm 2.3$ & $<\mathbf{0 . 0 0 1}$ & $\mathbf{0 . 0 0 9}$ & $<\mathbf{0 . 0 0 1}$ & $\mathbf{0 . 0 1 6}$ \\
Odor & $1.4 \pm 2.2$ & $1.2 \pm 0.9$ & $3.6 \pm 2.8$ & $\mathbf{0 . 0 1 1}$ & 0.956 & 0.056 & $\mathbf{0 . 0 3 6}$ \\
Fatigue & $2.7 \pm 2.2$ & $5.8 \pm 2.5$ & $6.5 \pm 2.6$ & $<\mathbf{0 . 0 0 1}$ & $\mathbf{0 . 0 0 2}$ & $\mathbf{0 . 0 0 1}$ & 0.394 \\
Overall discomfort & $2.8 \pm 2.2$ & $5.2 \pm 2.1$ & $7.0 \pm 1.7$ & $<\mathbf{0 . 0 0 1}$ & $\mathbf{0 . 0 1 2}$ & $<\mathbf{0 . 0 0 1}$ & $\mathbf{0 . 0 0 5}$ \\
\hline
\end{tabular}

Results of the questionnaire [14] quantitating ten domains of comfort/discomfort of wearing a surgical mask (sm) and a FFP2/N95 mask (ffpm) compared to no mask on a scale from 0 (no discomfort at all) to 10 (maximal discomfort) depicted as mean \pm standard deviation

Significant results are indicated in bold 
Table 4. In general, the negative ratings for all items of discomfort increased consistently and significantly from sm to $\mathrm{ffpm}$. There were several-fold negative reports for the ffpm compared to $\mathrm{nm}$ and $\mathrm{sm}$ for breathing resistance. The relative aggravation in overall discomfort compared to the standard procedure for spiroergometric tests is shown in Fig. 2.

\section{Discussion}

This first randomized cross-over study assessing the effects of surgical masks and FFP2/N95 masks on cardiopulmonary exercise capacity yields clear results. Both masks have a marked negative impact on exercise parameters such as maximum power output $\left(P_{\max }\right)$ and the maximum oxygen uptake $\left(V \mathrm{O}_{2 \max } / \mathrm{kg}\right)$. FFP2/N95 masks show consistently more pronounced negative effects compared to surgical masks. Both masks significantly reduce pulmonary parameters at rest (FVC, FEV1, PEF) and at maximum load (VE, $\mathrm{BF}, \mathrm{TV})$. Furthermore, wearing the masks was perceived as very uncomfortable with a marked effect on subjective breathing resistance with the FFP2/N95 mask.

\section{Pulmonary function}

Spirometry showed reduced FVC, FEV1 and PEF with the surgical mask and even greater impairments with the FFP2/N95 mask. Wearing the FFP2/N95 mask resulted in a reduction of $V_{2}$ max by $13 \%$ and of ventilation by $23 \%$. These changes are consistent with an increased airway resistance [15]. Studies testing increased upper airway obstruction induced by added resistance at the mouth report similar effects on the lung functions parameter with increased breathing resistance [16]. The reduction in ventilation resulted from a lower breathing frequency with corresponding changes of the inhaling and exhaling time and a reduced tidal volume. This is in agreement with the effects of respiratory protective devices or additional external breathing resistance $[16,17]$. The increased breathing resistance, which is likely higher during stress, leads to an elevated breathing work and a limitation of the ventilation. The data of this study are obtained in healthy young volunteers, the impairment is likely to be significantly greater, e.g., in patients with obstructive pulmonary diseases [18]. From our data, we conclude that wearing a medical face mask has a significant impact on pulmonary parameters both at rest and during maximal exercise in healthy adults.

\section{Cardiac function}

Increased breathing resistance in ffpm and sm requires more work of the respiratory muscles compared to nm leading to higher oxygen consumption. Additionally, a significant proportion of cardiac output is directed via different mechanisms, e.g., sympathetically induced vasoconstriction, to the respiratory musculature [19]. Furthermore, the increased breathing resistance may augment and prolong inspiratory activity leading to more negative intrathoracic pressure (ITP) for longer durations. This assumption is supported by the findings on inspiration times which were higher while wearing a fm. Prolonged and more negative ITP increases the cardiac preload and may lead to higher SV at the one hand which is consistent with our results showing a statistical trend towards higher SV while wearing ffpm or sm [20, 21]. In addition, cardiac afterload increases because of an increased transmural left-ventricular pressure resulting in enhanced myocardial oxygen consumption [22]. In these healthy volunteers, functional cardiac parameters do not differ significantly at baseline, at maximal load and during recovery. However, there is a non-significant trend towards a higher cardiac work (Joule) compared to the test without mask. This is of relevance since significantly less watts $(-5 \%)$ was achieved in the tests with masks. The relation of cardiac power to the total power is approximately $10 \%$ lower with ffpm. These data suggest a myocardial compensation for the pulmonary limitation in the healthy volunteers. In patients with impaired myocardial function, this compensation may not be possible.

\section{Performance}

The measurements show that surgical masks, and to a greater extent FFP2/N95 masks, reduce the maximum power. $P_{\max }$ (Watt) depends on energy consumption and the maximum oxygen uptake $\left(V \mathrm{O}_{2 \mathrm{max}}\right)$. The effect of the masks was most pronounced on $V \mathrm{O}_{2 \max }$. Since the cardiac output was similar between the conditions, the reduction of $P_{\max }$ was primarily driven by the observed reduction of the arterio-venous oxygen content $\left(\mathrm{avDO}_{2}\right)$. Therefore, the primary effect of the face masks on physical performance in healthy individuals is driven by the reduction of pulmonary function. In addition, the auxiliary breathing muscles have been described to induce an additional afferent drive which can contribute to an increase of the fatigue effect [23-25].

The performance of several different populations may be significantly affected by face masks. For athletes the use of fm will reduce physical performance. Less pronounced but mechanistically similar effects have been observed for mouthguards [26-28]. The increased breathing resistance is especially problematic for patients with chronic obstructive pulmonary diseases. Patients with diffusion disorders have reduced capacity to compensate due to the reduced tidal volume. Another example of a population at risk is patients with heart failure. The observed mechanisms may lead to more severe symptoms in individuals with impaired capacity for myocardial compensation. 


\section{Discomfort}

Health care professionals and others are faced with significant psychological distress during viral outbreaks [29]. Measures to maintain the quality of life both during emergency situations and long term care are increasingly important. Adequate personal protective equipment and adequate rest are considered keys to reduce the risk of adverse psychological outcomes [29]. Our sample primarily consisted of physicians working at a university hospital who are very familiar with medical masks and have a positive attitude towards personal protection. Our data show that FM leads to severe subjective discomfort during exercise. FFP2/N95 masks are perceived as more uncomfortable than sm. In particular, breathing resistance, heat, tightness and overall discomfort are the items with the greatest influence on subjective perception. This finding is in agreement with the literature $[14,30]$. Wearing of $\mathrm{fm}$ is perceived as subjectively disturbing and is accompanied by an increased perception of exertion. It is likely that the masks negatively impact on the dynamics of perception especially at the limit of exercise tolerance [31, 32]. In addition to the severe impact on ventilation, the data suggest the associated discomfort as a second important reason for the observed impairment of physical performance.

\section{Limitations of the study}

The sample consisted of relatively young, healthy, male participants. The data cannot be extrapolated to other populations but set the stage to assess the effects of the face masks in elderly and in patients with pulmonary and with cardiac diseases. This study is the largest cross-over study to date comparing acute cardiopulmonary effects with and without common face masks, however, independent repetition and larger sample size is always welcome. The external validity concerning surgical masks (relevant leakage to eyes and ears in daily life) may be reduced because of the laboratory conditions where the sm was completely sealed by the spirometry mask. Cardiac parameters obtained by impedance cardiography may be overestimated using absolute values [33]. However, thoracic impedance cardiography is well established for the quantification of intra-individual changes in SV and CO [34-36].

\section{Conclusion}

Medical face masks have a marked negative impact on cardiopulmonary capacity that significantly impairs strenuous physical and occupational activities. In addition, medical masks significantly impair the quality of life of their wearer.
These effects have to be considered versus the potential protective effects of face masks on viral transmissions. The quantitative data of this study may, therefore, inform medical recommendations and policy makers.

Acknowledgement Open Access funding provided by Projekt DEAL. We thank the volunteers from the staff of Leipzig University who participated in the study.

\section{Compliance with ethical standards}

\section{Conflict of interest None.}

Open Access This article is licensed under a Creative Commons Attribution 4.0 International License, which permits use, sharing, adaptation, distribution and reproduction in any medium or format, as long as you give appropriate credit to the original author(s) and the source, provide a link to the Creative Commons licence, and indicate if changes were made. The images or other third party material in this article are included in the article's Creative Commons licence, unless indicated otherwise in a credit line to the material. If material is not included in the article's Creative Commons licence and your intended use is not permitted by statutory regulation or exceeds the permitted use, you will need to obtain permission directly from the copyright holder. To view a copy of this licence, visit http://creativecommons.org/licenses/by/4.0/.

\section{References}

1. CDC (2020) Recommendation regarding the use of cloth face coverings, especially in areas of significant community-based transmission

2. ECDC (2020) Using face masks in the community-reducing COVID-19 transmission from potentially asymptomatic or presymptomatic people through the use of face masks

3. RKI (2020) Robert Koch-Institut: Mund-Nasen-Bedeckung im öffentlichen Raum als weitere Komponente zur Reduktion der Übertragungen von COVID-19. Strategie-Ergänzung zu empfohlenen Infektionsschutzmaßnahmen und Zielen (3. Update). Epid Bull 19:3-5. https://doi.org/10.25646/673

4. WHO (2020) Advice on the use of masksin the context of COVID-19

5. Xiao J, Shiu EYC, Gao H, Wong JY, Fong MW, Ryu S, Cowling BJ (2020) Nonpharmaceutical measures for pandemic influenza in nonhealthcare settings-personal protective and environmental measures. Emerg Infect Dis 26(5):967-975. https://doi. org/10.3201/eid2605.190994

6. Leung NHL, Chu DKW, Shiu EYC, Chan K-H, McDevitt JJ, Hau BJP, Yen H-L, Li Y, Ip DKM, Peiris JSM, Seto W-H, Leung GM, Milton DK, Cowling BJ (2020) Respiratory virus shedding in exhaled breath and efficacy of face masks. Nat Med 26(5):676680. https://doi.org/10.1038/s41591-020-0843-2

7. Shiu EYC, Leung NHL, Cowling BJ (2019) Controversy around airborne versus droplet transmission of respiratory viruses: implication for infection prevention. Curr Opin Infect Dis 32(4):372379. https://doi.org/10.1097/qco.0000000000000563

8. CDC (2019) Determination of particulate filter efficiency level of N95 series filters against solid particulates for non-powered, air-purifying respirators standard

9. Loeb M, Dafoe N, Mahony J, John M, Sarabia A, Glavin V, Webby R, Smieja M, Earn DJ, Chong S, Webb A, Walter SD (2009) 
Surgical mask vs N95 respirator for preventing influenza among health care workers: a randomized trial. JAMA 302(17):18651871. https://doi.org/10.1001/jama.2009.1466

10. Radonovich LJ Jr, Simberkoff MS, Bessesen MT, Brown AC, Cummings DAT, Gaydos CA, Los JG, Krosche AE, Gibert CL, Gorse GJ, Nyquist AC, Reich NG, Rodriguez-Barradas MC, Price CS, Perl TM (2019) N95 respirators vs medical masks for preventing influenza among health care personnel: a randomized clinical trial. JAMA 322(9):824-833. https://doi.org/10.1001/ jama.2019.11645

11. Johnson AT (2016) Respirator masks protect health but impact performance: a review. J Biol Eng 10:4. https://doi.org/10.1186/ s13036-016-0025-4

12. Blocken BMF van Druenen T, Marchal T (2020) Towards aerodynamically equivalent COVID-19 $1.5 \mathrm{~m}$ social distancing for walking and running

13. Quickcalcs G (2018) Random numbers

14. Li Y, Tokura H, Guo YP, Wong ASW, Wong T, Chung J, Newton E (2005) Effects of wearing N95 and surgical facemasks on heart rate, thermal stress and subjective sensations. Int Arch Occup Environ Health 78(6):501-509. https://doi.org/10.1007/s0042 0-004-0584-4

15. Lee HP, de Wang Y (2011) Objective assessment of increase in breathing resistance of N95 respirators on human subjects. Ann Occup Hyg 55(8):917-921. https://doi.org/10.1093/annhyg/mer06 5

16. Melissant CF, Lammers JW, Demedts M (1998) Relationship between external resistances, lung function changes and maximal exercise capacity. Eur Respir J 11(6):1369-1375. https://doi. org/10.1183/09031936.98.11061369

17. Louhevaara VA (1984) Physiological effects associated with the use of respiratory protective devices. A review. Scand J Work Environ Health 10(5):275-281. https://doi.org/10.5271/sjweh .2327

18. Kyung SY, Kim Y, Hwang H, Park JW, Jeong SH (2020) Risks of N95 face mask use in subjects with COPD. Respir Care 65(5):658-664. https://doi.org/10.4187/respcare.06713

19. Harms CA, Wetter TJ, McClaran SR, Pegelow DF, Nickele GA, Nelson WB, Hanson P, Dempsey JA (1998) Effects of respiratory muscle work on cardiac output and its distribution during maximal exercise. J Appl Physiol 85(2):609-618. https://doi.org/10.1152/ jappl.1998.85.2.609

20. Convertino VA, Cooke WH, Lurie KG (2005) Inspiratory resistance as a potential treatment for orthostatic intolerance and hemorrhagic shock. Aviat Space Environ Med 76(4):319-325

21. Ryan KL, Cooke WH, Rickards CA, Lurie KG (1985) Convertino VA (2008) Breathing through an inspiratory threshold device improves stroke volume during central hypovolemia in humans. J Appl Physiol 104(5):1402-1409. https://doi.org/10.1152/jappl physiol.00439.2007

22. Cheyne WS, Harper MI, Gelinas JC, Sasso JP, Eves ND (2020) Mechanical cardiopulmonary interactions during exercise in health and disease. J Appl Physiol 128(5):1271-1279. https:// doi.org/10.1152/japplphysiol.00339.2019

23. Amann M, Blain GM, Proctor LT, Sebranek JJ, Pegelow DF, Dempsey JA (2011) Implications of group III and IV muscle afferents for high-intensity endurance exercise performance in humans. J Physiol 589(Pt 21):5299-5309. https://doi.org/10.1113/ jphysiol.2011.213769

24. Amann M, Proctor LT, Sebranek JJ, Pegelow DF, Dempsey JA (2009) Opioid-mediated muscle afferents inhibit central motor drive and limit peripheral muscle fatigue development in humans. J Physiol 587(1):271-283. https://doi.org/10.1113/jphys iol.2008.163303

25. Blain GM, Mangum TS, Sidhu SK, Weavil JC, Hureau TJ, Jessop JE, Bledsoe AD, Richardson RS, Amann M (2016) Group III/IV muscle afferents limit the intramuscular metabolic perturbation during whole body exercise in humans. J Physiol 594(18):53035315. https://doi.org/10.1113/jp272283

26. Caneppele TMF, Borges AB, Pereira DM, Fagundes AA, Fidalgo TKS, Maia LC (2017) Mouthguard use and cardiopulmonary capacity - a systematic review and meta-analysis. Sports Med Int Open 1(5):E172-e182. https://doi.org/10.1055/s-0043-117599

27. Francis KT, Brasher J (1991) Physiological effects of wearing mouthguards. Br J Sports Med 25(4):227-231. https://doi. org/10.1136/bjsm.25.4.227

28. Bailey SP, Willauer TJ, Balilionis G, Wilson LE, Salley JT, Bailey EK, Strickland TL (2015) Effects of an over-the-counter vented mouthguard on cardiorespiratory responses to exercise and physical agility. J Strength Cond Res 29(3):678-684. https://doi. org/10.1519/jsc.0000000000000668

29. Kisely S, Warren N, McMahon L, Dalais C, Henry I, Siskind D (2020) Occurrence, prevention, and management of the psychological effects of emerging virus outbreaks on healthcare workers: rapid review and meta-analysis. BMJ 369:m1642. https://doi. org/10.1136/bmj.m1642

30. Powell JB, Kim J-H, Roberge RJ (2017) Powered air-purifying respirator use in healthcare: Effects on thermal sensations and comfort. J Occup Environ Hyg 14(12):947-954. https://doi. org/10.1080/15459624.2017.1358817

31. Damasio A, Carvalho GB (2013) The nature of feelings: evolutionary and neurobiological origins. Nat Rev Neurosci 14(2):143152. https://doi.org/10.1038/nrn3403

32. Strigo IA, Craig AD (2016) Interoception, homeostatic emotions and sympathovagal balance. Philos Trans R Soc Lond B Biol Sci 371:1708. https://doi.org/10.1098/rstb.2016.0010

33. Siebenmann C, Rasmussen P, Sørensen H, Zaar M, Hvidtfeldt M, Pichon A, Secher NH, Lundby C (2015) Cardiac output during exercise: a comparison of four methods. Scand J Med Sci Sports 25(1):e20-27. https://doi.org/10.1111/sms.12201

34. Astorino TA, Edmunds RM, Clark A, King L, Gallant RA, Namm S, Fischer A, Wood KM (2017) High-intensity interval training increases cardiac output and $V \mathrm{O}_{2 \max }$. Med Sci Sports Exerc 49(2):265-273. https://doi.org/10.1249/mss.0000000000001099

35. Daussin FN, Ponsot E, Dufour SP, Lonsdorfer-Wolf E, Doutreleau S, Geny B, Piquard F, Richard R (2007) Improvement of $V \mathrm{O}_{2 \max }$ by cardiac output and oxygen extraction adaptation during intermittent versus continuous endurance training. Eur J Appl Physiol 101(3):377-383. https://doi.org/10.1007/s00421-007-0499-3

36. Lepretre PM, Koralsztein JP, Billat VL (2004) Effect of exercise intensity on relationship between $V \mathrm{O}_{2 \max }$ and cardiac output. Med Sci Sports Exerc 36(8):1357-1363. https://doi.org/10.1249/01. mss.0000135977.12456.8f 